\title{
What is an advert? A sociological perspective on marketing media
}

\author{
Abstract \\ This paper draws on a conceptual vocabulary developed in science and technology studies to \\ advance a sociological theory of objects in marketing. Analysing a single advertising medium, it \\ shows that marketing objects can exist simultaneously in multiple forms as physical artefacts, \\ political decisions, legal entities and economic values. Armed with this understanding, the paper \\ explores the ability of actors to manipulate these realities in their favour and investigates how it \\ is possible to turn public space on a city street into an advertising object. Using John Law's \\ notion of fractional objects, the paper proposes an analytic framework to open up new objects for \\ critical intervention and reflection.
}

\section{Keywords}

Advertising, fractional object, media, outdoor, science and technology studies, social studies of marketing, telephone box. 


\section{Introduction}

What do we see when we look at advertisements? Information, ideological images, quality signals, cultural values, promotional culture, peripheral cues, psychological pollution?

Whichever interpretation we find most compelling, it is common to see advertising as a form of message rather than a form of media.

But advertisements are not just messages. They are delivered to audiences through screens, machines, street furniture, paper and speakers, each of which influences advertisers, advertisements and consumers in different ways. The task for marketers, in particular, is to find a way to use these objects for advertising without turning them into adverts (Dahlén and Edenius, 2007). As Friedstad and Wright's (1999) persuasion knowledge model tells us, when a consumer perceives a text as an attempt to persuade them, it loses its power to persuade. Consequently, contemporary consumer resistance to advertising organized by the likes of AdBusters, Brandalism and Resistance a L'Agression Publicitaire hijacks advertising objects to reveal their persuasive ambitions.

In these ways and more, marketers and consumers question what constitutes an advertising object. This paper draws on an analytic vocabulary developed in science and technology studies (STS) to answer this question sociologically. It analyses a single advertising object and shows that it has multiple existences that work together to form an advertising object that is seemingly immune to critical interventions.

To explain this, the paper returns to Law's object theory. It considers objects as fractional that is, patterns of 'different realities' rather than a single, unified 'thing' (Law 2004: 13). Here, the paper proposes a framework that compares an object's enacted modes (as advertisements, phone boxes and so on) with the enacted realities that they exist in (the physical world, legal 
documents and economic markets, for instance). The paper concludes that a successful advertising object is a complex relationship between enacted modes and enacted realities and that critical interventions are doomed to fail if they only focus on one mode or reality in isolation. In the sections that follow, the paper briefly outlines the main tenets of an STS approach to marketing that motivates the study. This is followed by an exposition of key concepts in Law's object theory. These are then employed to trace the work involved in the construction of a telephone kiosk by an advertising agency on a public street in a UK city. Finally, the case is related to wider discussions and implications for critical interventions are discussed.

\section{Taking things seriously}

Material and technical objects have increasingly attracted marketing theorists' attention. Setting the scene for this work, Cochoy (2009: 32-33) argues that marketing and consumer research has been 'trapped into a kind of vicious circle' in which the objects of consumption are taken 'as some inert substratum' or 'reduced to what humans think about them or do with them'. He uses advertisements to demonstrate the challenges objects pose to dominant marketing theories. Cochoy (2010: 306) observes that ads:

are both intellectual and practical: they combine images and text, they mix the direct display of objects, facts and scenes with the comments and discourses aimed at giving them meaning and commercial appeal. How can we account for such a rhetoric which closely mixes the intellectual and the practical, the linguistic and the materialistic, the 'performative' and the 'performed'? 
In response to such challenges, contemporary marketing theorists have analysed a variety of objects using a conceptual vocabulary developed in the sociology of science (Araujo, 2007; Badje, 2013; Muniesa, 2014). This has allowed researchers to consider the powers of objects such as shopping bags (Hagberg, 2015) and water bottles (Brei and Tadajewski, 2015; Hawkins 2011) to shape consumer behaviour, as well as the performativity of intangible things such as market segments which produce and describe markets at the same time (Jacobi, Freund and Araujo, 2015; Cluley and Brown, 2015, Venter, Wright and Dibb 2015). This stream of literature has also exposed how powerful actors shape the form of objects - and, through this, markets - to meet their economic and political interests (Cluley, 2018; Denegri-Knott and Tadajewski, 2010, 2017).

One benefit of this latter approach is that it focuses attention not only on the properties of objects but also the heterogeneous interconnected network of relations behind them: their immateriality (Harman, 2015). This comprises the socio-technical-legal infrastructures that help bring particular versions of an object into being and a recognition that an object may exist in multiple forms across a network of relationships. A shopping bag, for example, is not only a convenient device for transporting items one has purchased, it is a branded object, it determines how much one can purchase in a single shopping trip, it constrains the shape of items stocked in shops, it is also increasingly a threat to the environment and a vehicle for tax-revenue generation. Cochoy $(2009,2010)$ calls for an archaeology of present times to uncover the different forms that a single marketing object occupies - that is, to explore how and why particular forms of an object emerge, compete and stabilise into a seemingly single real object at a particular point in time. However, to consider the hidden politics and power relations behind objects, at the 
same time as analysing their form, the present study employs Law's (2002a, 2004) object theory as a conceptual framework. Law's work explicitly encourages us to consider both the affordances of objects and the relationships between different actors who seek to make their version of an object more real than others.

\section{Law's object theory}

In a series of contributions, Law seeks to go beyond a Euro-American cultural tendency to binarism when examining objects that constitutes them as either coherent singular entities or dislocated fragments. Instead, Law proposes that we can consider an object as existing in different versions that are 'realized' or enacted within specific settings and practices by specific actors (Law 2009: 242). Enactment is a term Law uses repeatedly to refer to processes through which a social world is continuously created and recreated from within - similar to concepts of performativity and structuration (see Law and Urry, 2004).

For example, Law (2009) offers an analysis of a Eurobarometer survey on European citizens' attitudes to farm animal welfare. He traces the realities it enacts, referring to them as layers. On the surface, the survey enacts a European consumer that cares about farm animal welfare. But underneath this layer, the survey also enacts a legitimate public opinion for the political agenda of an animal welfare lobby group and a neoliberal subjectivity of the consumer as rational-ethical decision-maker. In other work, Law (2002b: 96) even argues that physical space itself is not a pre-existing 'neutral container' within which objects happen to exist but that objects and space create each other in what he calls 'sedimented enactments'.

This consideration of how realities are enacted, by whom and for what purpose is what Law refers to as ontological politics. It refers to the hidden politics and power relations within 
actors' reality-making practices and the various ways actors expel or defer multiple versions of an object in order to produce an object as singularly real. Law (2004: 250) argues that by articulating the realities made through enactment we can examine their coherence and start to 'work on and in the fissures' between them 'in the hope of making other realities'. Thus, the first step in understanding ontological politics is to describe the multiple existences of an object - to expose deferred multiplicity - and this requires us to capture the space between the single and the plural. For this, Law uses the metaphor of fractionality, drawing primarily from anthropologist Strathern's (1991) use of fractals in the physical sciences as a metaphor for complex social relations.

For background, fractal geometry emerged when physical scientists found that some questions, which one might assume have single, concrete answers, such as 'how long is a country's coastline?', actually produce multiple equally correct answers depending on the scale at which one is measuring it. Fractal imagery was useful to Strathern because it does not exhibit exactly the same structure when a part is magnified; rather similar structures appear on all scales. This helped Strathern to explain unexpected similarities - or partial connections - between societies and individuals without reproducing the idea of a priori wholes, parts or essences.

Thinking in these terms, Law describes a fractional object as 'more than one and less than many' (2004: 62). As Law (2004: 75 emphasis added) puts it, a fractional object is enacted in different practices and in different sites but 'those differences are managed in a way that also secures the continued possibility of the singularity... at each particular location'. By way of example, Christensen, Hillersdal and Holm (2017) conceive appetite as a fractional object. While generally understood as a fixed concept associated with the body, they argue that, in practice, appetite exists in many different but similar versions in different settings. It is physiological, 
biochemical, psychological, discursive and more besides. The point is that the scale at which an object (whether a shopping bag, coastline or appetite) is observed determines the 'reality' that is described.

In this sense, Law's concept of fractionality encourages us to think not only about the variety of ways the same object exists but also how those realities relate to each other in what Law refers to as the object's hinterland. A hinterland is the networks of practices that create, contradict and support seemingly singular, stable objects. They are spaces of inconsistencies, conflicting practices and views that have been silenced to ensure that a specific reality is maintained. Simply, hinterlands are spaces of power and ontological politics.

Law offers further terms to analyse the complexity that results from considering objects as fractional. In any social world, a particular form of an object structures activities. This is its presence. Presence depends on what is made manifest absent. That is, a form of an object that is absent but recognised as relevant to, or represented in, presence (Law 2004: 84, 157). For example, Freund (2014) argues that advertising and advertising media function not only to capture attention through the presence of brands and persuasive rhetoric but simultaneously distract attention away from important negative or harmful aspects of the brand: to make its corporate motives, methods and effects absent.

The key tenet for Law is that presence is always incomplete. Singularity is a characteristic of an object produced through mechanisms that make multiplicity invisible. But it is always there, in the object's hinterland. Sustaining what is present thus depends on making other realities disappear. Law (2004: 85) refers to this as Othering. It occurs when relations are black-boxed or enacted in its presence as insignificant or impossible. It is a form of political repression (Law, 2004: 170). Othered forms do not cease to exist, they are silenced. 
To bring these strands together, we can see that contemporary marketing theorists have coalesced around STS as a way of examining how material objects shape social interactions and influence markets and consumption. Law's work is particularly useful because it provides a conceptual vocabulary with which to expose and analyse the ontological politics, contested and uncontested relationships, presences and absences that produce the form of objects in markets. Informed by this perspective, and taking a lead from Cochoy's (2010) reference to advertising as an exemplary marketing object, the paper sets out to ask 'what is an advert?'. More specifically, it seeks to explore the multiple co-existing realities of an advertising object and the ontological politics that influence these realities.

\section{Method and case analysis}

The STS-inspired marketing literature has turned to outdoor advertising as a particularly revealing example of the materiality of advertising. Outdoor (or out-of-home) advertising refers to advertising in publicly accessible environments. It appears on billboards, posters, and street furniture: transit objects such as buses, and ambient objects such as public toilets and petrol pumps. It has attracted interest because it is a form of advertising that is adept at occupying different physical objects despite attracting criticisms and resistance (see Baker, 2007). McFall (2004: 112) notes outdoor advertising's long-standing 'ingenious use of a diverse, even bizarre' range of devices. Pedestrian crossings, drain covers, pavements and bollards have all been turned into advertising media. Cochoy $(2016,143)$ notes how bus shelters simultaneously function as 'advert shelters', creating a pause in city-dwellers' experience for engagement with an ad. Such objects frequently have several purposes such that the advertising may not be obvious. While some advertising objects such as Morris columns were invented to combat fly-posting (Parry 
2011), advertiser-funded street furniture has been promoted as a way to reduce the cost to public authorities of providing and maintaining it (Iveson, 2012).

Building on this literature, the paper analyses a new outdoor advertising medium that was erected in a mid-sized city in the Midlands region of the UK. Focusing on the first successful application for outdoor advertising submitted to the Local Planning Authority (LPA) after the study began, planning processes, policies, laws and regulations, companies and actors, and industry structures are examined.

Interpreting the data using Law's terminology, we found it useful to distinguish two types of enactment. First, the object can be described in terms of its primary function (for example, an advert, a bus stop, a shelter from rain). We describe this as the enacted mode of the object. It helps us see that a single object can be enacted as a variety of different things. Second, the object can be defined in terms of the particular context it helps to enact (physical, legal, economic, for example). We refer to this as the enacted reality of the object. These terms add specificity to what have so far been described as layers, sediments, social worlds, existences and realities in existing object theory.

In what follows, we illustrate these concepts by describing the enacted mode of the advertising object within four enacted realities. This account is, of course, partial and driven by the theoretical interest set out above. It is not intended to preclude the possibility of different interpretations of these events and objects. In terms of the presentation of the data, the analysis is based on publicly available documents with references provided to external sources. Anonymity has not been extended to the actors involved. The primary reason for this is that an internet search would be enough to locate many documents. Moreover, almost all of the documents are in the public domain precisely to allow scrutiny. 


\section{Physical Objects}

The most immediate enacted mode of the object is physical. It is a telephone kiosk located on a public highway in a mid-sized UK city centre (see Image 1). The kiosk is solar powered with three glass-panelled sides all of which are the standard size for advertising posters. There is no front door to the kiosk as on traditional red British phone boxes. A coin operated telephone unit is positioned at approximately half the height of the kiosk and the kiosk itself is wider than common British Telecom phone boxes. The telephone unit in the kiosk displays the name 'Infocus Public Networks'. On the outside, above the glass panel display, the kiosk has a sticker on it displaying the text 'infocus-media.org.uk'.

[Insert Image 1 here]

The kiosk was erected on the street on Saturday, 20th June 2015. Construction took place on a typically busy Saturday morning. The street was occupied with shoppers walking between the bus stops, taxi rank, large hotel and a shopping precinct.

The kiosk was delivered on an unmarked grey van. Construction was fairly haphazard as four workers in high-visibility jackets cut into the pavement and manoeuvred the kiosk into place behind a hastily-erected barrier. As they did so, passers-by were squeezed into a narrow corridor on the pavement with some being pushed on to the road. Taxi drivers from a neighbouring taxi rank stood and watched.

During the observation, no one stopped to question the workmen nor did they volunteer to speak to any of the observers including the researchers. None of the workmen were wearing any branded attire identifying who they were working for. The only identifying device was a sign 
placed next to the construction site. This was partially obscured with a stuck-on sheet of paper. The workers did not appear to be working from a plan and there was no evidence of measuring equipment. Convenient pavement slabs were pulled up, the kiosk was sited and the existing slabs cut to fit around the kiosk's stanchions. Once installed, the construction team packed their tools away and left.

Over the first few months after its installation, the researchers returned to the kiosk irregularly. On every occasion the telephone inside had no dial tone and at the time of writing this remains the case. Lifting the telephone receiver, the LCD display previously read 'OUT OF ORDER' but now stays blank. At each visit, an advertisement was displayed on the kiosk (see Image 1). Indeed, while people were observed passing by the object, none were seen using the telephone inside or even attempting to do so. Occasionally, passersby glanced at the ads, or could be overhead referring to the products they promoted. More regularly, the advert, like the phone, was simply ignored. The box, itself, was used for shelter or to lean against.

\section{Proposed Objects}

Before the physical object could be constructed on the street, it existed as a proposed object. It had to be granted 'prior approval' from the LPA - Nottingham City Council's Planning Department. This process started in April 2013 after Infocus Public Networks submitted an application to Nottingham City Council's Planning Department for the 'siting and appearance of a public payphone' (Parkin 2013). The application comprised a Supporting Letter, Siting Map and Site Photo (see Image 2). The three documents perform three interrelated tasks. They describe the physical object, classify it and propose a world of responsibilities and rights for 
actors in the planning process. In short, as well as describing the proposed object, they enact a particular reality for it.

[Insert Image 2 here]

The Site Photo (Image 2) offers a seemingly direct representation of proposed object in place during the daytime. Yet, the image omits a number of important features. It is directed away from the city centre. If the camera was angled through 180 degrees, it would show a much busier image, with bus stops, a large taxi rank, a hotel and the entrance to a shopping precinct. Indeed, the image includes no people or traffic. Finally, the Site Photo describes the object itself. But the shape that is imposed on the picture to represent the location of the proposed 'phone kiosk' only illustrates the object's footprint. It does not impose a three-dimensional object on to the picture. Comparing the Site Photo (Image 2) against the photographs taken by the researchers (Image 1) illustrates these differences.

Despite including reality-claiming devices such as a scale and compass, the Site Map similarly edits the local environment. It shows six trees, four bike racks and two public payphones. However, it leaves out the taxi rank, bus stops, pedestrian crossing and rubbish bin all of which lie directly in front the proposed site. This has the effect of making the street seem less populated with street furniture.

The Supporting Letter does similar work. It describes the object as a 'kiosk', 'payphone', and 'electronic communication apparatus, namely a public payphone' and produces it as a necessary public amenity. This claim is itself fairly surprising considering the widespread availability of mobile phones and infrastructure that supports almost complete network coverage across the UK and the fact that two payphones are already in place within 10 metres of the 
proposed site (these are visible in Image 1). Acknowledgment of these existing objects only appears in the statement that, unlike existing payphones in the area, the proposed object will 'accommodate wheelchair users' and offer a 'significantly' lower minimum call cost.

Read together, the three documents do not describe the object, its environment nor use in the same way. The proposed object is multiple. The Supporting Letter, for example, highlights existing street furniture and traffic left out of the Site Map and Site Photo. Even the position of the proposed object changes. The proposed location on the Site Photo is spaced back from the edge of the pavement in keeping with existing street furniture. On the Site Map, it is positioned much closer to the edge of the curb. The documents also describe how the object will be used in different ways. It is notable here that advertising is only mentioned as a possible use of the proposed object. The Supporting Letter acknowledges that the kiosk may be used to display advertising but enacts it as a form of anti-advertisement. It states:

[the style of kiosk is] completely visible to the public and to surveillance cameras, making them quite unsuitable for the facilitation of anti-social or criminal activities...these payphones do not facilitate easily advertising by sex workers.

These documents, then, not only describe what the physical object will look like in situ, they attempt to reconcile the multiplicity of the object, and insist on its singularity, by separating it from undesirable uses such as advertising by sex workers. In Law's terminology, this effectively makes the enacted mode of the object as advertising medium manifest absent. To achieve this, the proposed object intersects with another enacted reality, a legal world, which we describe in the next section. 
The proposal documents not only describe the object, they also enact the power of different actors. In particular, Infocus is empowered as an electronic communications network provider in accordance with the UK Government's National Planning Policy Framework (NPPF) (Ministry of Housing, 2012). This grants them the right to erect communications equipment in public space. The decision by the UK's communications regulator, Ofcom, in 2009 to grant Infocus Public Networks Ltd - officially registered as an advertising agency - the power to provide a communications network in the UK was actually challenged formally by Nottingham County Council. They observed that 'payphone design ha[s] involved extended advertising space... [and] the payphone itself was a secondary facility to enable the service provider to benefit from Code powers' (Ofcom 2018: 1.15). However, this claim failed because it lacks the re-occurring practices of the legal hinterland that generate the object as a telecommunications offering. As such, Ofcom help enact the object as 'further[ing] the interests of consumers...by promoting competition' (Ofcom 2018: 1.3). As a result, Infocus entered the proposed world with power granted from Ofcom.

The proposed object produced in the application documents further disempowers the LPA by highlighting previous regulatory decisions that make it more difficult to enact the object as an advertising medium. The Supporting Letter states that 'the High Court has decided recently that advertising on payphones is subject to a complete and self-contained legal code' such that planning authorities 'are not entitled to take into account potential advertising on payphones'. It explains that, in similar applications, 'where the need for additional payphones was challenged...the Inspector attached little weight to such objections [as] consumers were entitled to choice in the availability of the communications services they wished to use'. 
Yet despite the attempt to disempower the LPA, Infocus' application was rejected on June $7^{\text {th }} 2013$ (Nottingham City Council 2013). The LPA offered two justifications for their decision. First, they claimed that the proposed object 'would introduce an element of clutter along a carriageway edge that is already populated with street furniture, and would inhibit the opportunity for passengers to alight from taxis using the adjacent taxi rank'. The Decision Letter explains that the site 'is already subject to numerous items of street furniture' including 'street trees (with guards and grilles)', 'lamp columns', 'post boxes', 'a litter bin', and a 'double telephone kiosk'. Second, the proposed object was judged to be 'not consistent with other street furniture within Nottingham City Centre'. The LPA noted that the application did not include 'dimension drawings'. These are important as it is required that $500 \mathrm{~mm}$ must be 'left clear of the edge of the carriageway'.

Far from offering a public amenity, then, the local authority enacted the object as an obstruction. Indeed, they recommended that the 'application be refused in the interests of pedestrian amenity'. These judgements were supported by reference to sections BE1, BE3 and BE18 of Nottingham City Plan. Put otherwise, just as Infocus attempt to perform the object through reference to their preferred rules and regulations, the LPA enacts it differently by referring to other rules and regulations in the object's hinterland. Each of these judgements can be read as a challenge to the way Infocus generate the object and a challenge to the way Infocus enact the roles, rights and responsibilities of the actors involved to do so. It was not just the application that was rejected; it was all of the mechanisms that sought to make Infocus' preferred reality singular.

\section{Legal objects}


In settling the proposal, both sides drew on legal powers to shape the physical world. Infocus appealed the LPA's decision and, in effect, requested that a higher authority intervene. To do so, they explicitly enact the proposed object as a legal entity. The appeal was submitted to The Planning Inspectorate on $26^{\text {th }}$ July 2013 under Section 78 of the Town and Country Planning Act 1990 and followed a procedure of written representations. The Inspectorate rejected both reasons set out by the LPA and granted Infocus' application approval on $8^{\text {th }}$ May 2014. This was supported by the Inspector's site visit on Wednesday, 23rd April 2014.

Behind this judgment was a hinterland of decisions about the nature of outdoor advertising. UK planning regulations define an advertisement, generally, as:

any word, letter, model, sign, placard, board, notice, awning, blind, device or representation, whether illuminated or not, in the nature of, and employed wholly or partly for the purposes of, advertisement, announcement or direction, and (without prejudice to the previous provisions of this definition) includes any hoarding or similar structure used or designed, or adapted for use and anything else principally used, or designed or adapted principally for use, for the display of advertisements.

Such advertisements exist in one of three legal states in the UK. One class does not need formal consent from an LPA to be erected. It includes historic signs on buildings and adverts only visible from inside a property. A second class has 'deemed consent'. This means that explicit consent from an LPA is not needed provided the physical object conforms to other regulations. All other adverts require consent from an LPA. The Town and Country Planning Regulations 2007 grant 'Advertisements on telephone kiosks' deemed consent (Class 16). This allows 
advertisements to be displayed on the glazed surface of a telephone kiosk provided they meet certain conditions and limitations...Commercial advertisements are limited to one face of a telephone kiosk. The advertisements should be placed so as to avoid interference with the lines of sight for closed circuit television cameras... When kiosks are sited in group layouts...in order to minimise the visual impact, only alternate faces should carry advertisements and using consecutive faces is not permitted.

This classification was supported by a High Court Ruling in 2010 (EWHC 3309). It judged that LPAs cannot consider the presence of advertising on phone boxes when making their decisions about whether a proposed phone box meets the requirements for deemed consent.

As we have seen, Infocus refer to this case in the Supporting Letter. But it turns out that it was, in fact, Infocus that brought it to the High Court three years earlier. The ruling was made against the Secretary of State and the Mayor of London after they refused to grant deemed consent for seven telephone kiosks proposed by Infocus on the grounds that the proposed objects 'would detract from the townscape by adding visual clutter to the street' (2010, EWHC 3309 paragraph 16). The London LPA explained that 'the use of the kiosk for display of advertisements on the public highway makes the appearance of the kiosk more prominent in the street scene and detracts from the generally dignified character of the City streets'. In short, the London LPA authorities enacted the proposed and physical objects as adverts. They argued that since the objects are 'being used for the display of advertisements... Such advertisements, and the telephone kiosk itself, cause visual clutter to the detriment of the street scene' (2010, EWHC 3309 paragraph 22). Here is recognition of an alternative reality for the physical object that has been othered in its hinterland. It enacts it as a medium for advertising. 
In this case, Infocus had already installed kiosks, so the LPA issued enforcement notices on them, thereby enacting the physical objects as advertisements and street clutter it had the power to remove. The High Court Judge confirmed that an LPA does have the 'powers to stop an object being used to display advertising that represents a "substantial injury to the amenity of the locality or a danger to members of the public"' (2010, EWHC 3309 paragraph 64). These powers, the judge points out, are described in the publication "“Outdoor Advertisements and Signs: a guide for advertisers" which is a government booklet which explains how the system of advertisement control works in England' (2010, EWHC 3309 paragraph 64). This document allows LPAs to issue a 'discontinuance notice' to an advertising provider which compels them to remove their advertising site a minimum of 8 weeks from receiving the notice.

However, the Judge found that 'the existence of advertising material on a telephone kiosk that is otherwise sited appropriately in the planning context and has an intrinsically acceptable appearance' should not be 'a material consideration in deciding whether prior approval should or should not have been given to the erection of that kiosk'. As a result, the Court overturned five of the seven appeal decisions and enacted the object legally, nationally and from this point on, as a telephone kiosk and public amenity not an advert. It meant that neither the London LPA nor Nottingham LPA were able to consider the presence of advertising in their judgements about the proposed object.

Infocus' appeal against Nottingham LPA was consequently successful. Summarising the judgement in an Appeal Decision Letter, the Inspector stated that the proposed kiosk 'would be similar to a number of nearby bus shelters and British Telecom kiosks, and as such its appearance would not be inconsistent with other street furniture in the City Centre as the Council contends'. He also concluded that while the kiosk 'would, by definition, increase the clutter of 
street furniture' at the proposed site, because there was already 'a line of trees and street furniture which includes phone kiosks, cycle racks, waste bins, lighting columns, post boxes and a poster display unit', it would not affect 'the quality of the public realm'. The Inspector was 'satisfied that the convenience of those pedestrians boarding and alighting taxis would not be compromised'. These legal practices shape the reality of the object by enacting it as a legal entity (simultaneously deferring alternative realities) which then interferes first with the proposed object and then the physical one. Put simply, the Inspector was satisfied that the object met all its legal requirements - as a phone box.

\section{Economic objects}

The telephone kiosk is an economic object. As a phone box, it generates revenue by providing communications services to consumers. Public accounts submitted by Infocus to Companies House reveal that 'Kiosk revenue' amounted to $£ 26,987$ (Infocus Public Networks Ltd 2015) and $£ 17,641$ (Infocus Public Networks Ltd 2014). The accounts define this revenue as 'the monies taken in the use of the kiosks for making telephone calls'.

As an advertising medium, the object also generates revenue by selling space to advertisers. According to Infocus' rate card at the time of writing, a two week poster campaign package of seven panels in Nottingham costs $£ 2,100$ excluding production or $£ 2,860$ including

production. This includes a $15 \%+5 \%$ agency commission. Public accounts submitted by Infocus to Companies House reveal that 'Sales' amounted to $£ 1,271,668$ (2015) and $£ 1,051,599$ (2014). This is defined as 'the sales value of services provided' - presumably advertising services. In 2015, Infocus was acquired by JCDecaux - the world's largest provider of outdoor media (Infocus Public Networks Ltd 2015). 
In the reality-making process of the UK State, the economic object not only generates revenues for a specific company. It contributes to economic growth as part of the development of high quality communications infrastructure (Ministry of Housing 2012, 12). It is a public amenity that is efficiently delivered by "the market". As such, the UK Government explicitly precludes LPAs from questioning the need for new telephone kiosks on the basis that it improves choice for consumers. Yet, there is declining use of public payphones nationally - British Telecom started to sell advertising space on their phone boxes in 2000 to make up for their declining revenues (Marketing Week, 2002).

The economic object also exists in the marketing world. Here, it is subject to the realitymaking practices of media owners, agencies, market researchers and advertisers. It is enacted as a valuable outdoor advertising media alongside billboards, bus shelters and so on in terms of the space it occupies, not the telecommunications service it supplies. The value of a telephone kiosk for the media owner is increased by the fact that they offer buyers of advertising space 'unavoidable' eye-level advertisements in locations frequented by many high-spending consumers such as shoppers and commuters where there are relatively few ads from competitors. As one media provider puts it, phone boxes are 'glass panels that face pedestrian footfall and passing vehicular traffic' (Bolton, 2014). Here, the reality of the telephone kiosk as public amenity is manifest absent and the object is enacted as a cost-effective way for advertisers to reach a vast number of consumers. No longer is it logical, then, to site telephone kiosks in remote areas where existing public access to telecommunications is sparse but rather to erect them within the densely populated areas of towns and cities.

The conflicting economic classification of the object is mirrored in the organizational arrangements of Infocus. If we return to the physical object, we remember the sticker for 
'infocus-media.org.uk' on the outside of the kiosk. Infocus Media operates a full website (Image 3) which states that 'we specialise in city centre poster campaigns across the UK'. There is no mention of providing telecommunication services among this promotional material. Rather, it includes site lists of their advertising spaces for each of the cities they operate in, their rate card, contact details and case studies. The construction and planning proposal of the object was, however, executed by Infocus Public Networks Ltd. The signage put up during construction included their logo and the telephone unit inside the kiosk does too. Infocus Public Networks Ltd is a regulated communications provider (Ofcom 2018). At the time of writing, they operate a single web page (Image 3). It describes the organization as 'the UK's third public payphone provider'. There is no mention of providing advertising services among this promotional material.

[Insert Image 3 here]

Here, the othered inconsistencies of the advertising hinterland are exposed. Infocus Public Networks Ltd began operating in 2008 after Infocus Media Ltd registered a change of name (Registrar of Companies 2008). Though they changed names, they did not change the registered nature of the business; it is not telecommunications activities (Codes 61100 or 61900) but an advertising agency (Code 73110). As such, all economic activity that Infocus Public Networks Ltd engage in are accounted for officially as advertising not telecommunications.

\section{The advertising object as a complex relationship}

By examining the different realities of a seemingly single advertising object, a sensible working hypothesis emerges: it is precisely because this object never stabilises as a single thing that it can 
exist as an advert. If it was only an advert, it would be subject to distinct rules which would grant particular actors the power to remove it. Yet, if it was routinized into a telephone box alone, it would face bleak prospects. It would be economically endangered and would, most likely, never have been proposed nor built.

This supports the interpretation that the object is a dynamic combination of its enacted realities and enacted modes. Enacted realities refer to the different worlds that the object exists within and helps to enact. In the present study, we have interpreted the object as occupying physical, proposed, legal and economic worlds. Enacted modes refer to forms of the object that are present and absent in a given enacted reality; here, a telecommunication device and an advertising medium. Distinguishing and comparing co-existing realities and modes allows us to chart the hinterland of this object and expose how actors strategically shape them in their favour.

Figure 1 explains the relationships between enacted modes and enacted realities involved in the case diagrammatically. The key point of this figure is that the object must be understood as all the relationships between these modes and realities, and more besides. In a sense, one could slice Figure 1 up, rearrange the order of the enacted realities (presented here in reverse chronological order, from its physical presence to the economic incentive), add further realities, and thereby provide a different analytical 'starting point' to reveal different relationships and enacted modes. Likewise, one could add onto this the practices of specific actors which enact particular modes, and other different ones, and identify silenced actors. This would then show how particular actors are able to enact new realities for an object by strategically manipulating its modes of existence in the hinterland. Put otherwise, one could also use the framework to investigate ontological politics.

[Insert Figure 1 here] 
In the physical reality, the object is present as an advertising medium (1). It exists to display advertising messages to passersby. Certainly, they are able to use the object for other purposes - including making calls, sheltering from the weather, lighting cigarettes and so on. Yet, even though the telephone might not work, and consumers might identify the object as a phone box, it functions primarily as an ad. The economic and proposed realms are manifest absences in this physical reality (2 and 3).

In the proposed reality situated rules were deployed in a tussle to enact the object not as advertisement but as a telecommunications device (4). Supported with reference to the physical reality (in the reality-claiming devices of Infocus' application) (5) and the legal reality (Infocus' reference to legal judgements) (6), it was eventually enacted as a public amenity that offers potential users improved choice. While there was some acknowledgement by all actors that the object may display advertising, they either struggle to make this present or intentionally make it absent.

The proposed reality is, in turn, manifest absent in the legal world. That is, the legal definition of the object was motivated by issues that emerged in the proposal process. It was, after all, Infocus' (2010) case at the High Court that forced legal actors to make the object present as a communications device (7). Infocus then ensure these judgements are present in the proposed reality (6) to silence and disempower competing actors (such as the LPAs) who try to enact the object in other ways (e.g. an advertisement or an eyesore). The outcome of these practices is that, in the legal reality, the object is both an advert and a communications device (8). It possesses the legal status of an advert with deemed consent. Yet when an actor challenges 
the deemed consent of the advertising object, the legal system enacts it as a communications device with its own legal backing.

Beyond the legal world there lies a hidden but obvious economic reality that sets the entire network of relations in motion. Enacted as an economic object, the phone box exists legally on the basis that it increases consumer choice and perfects the communications market (9). But this is a relatively minor component. In the economic reality, the object is enacted as an advertisement (10). The physical object is present in this reality in accruing economic value by allowing advertisers to communicate to their target audience (11). It might generate some revenue as a communications device but this is now insignificant (12).

Understood in these terms, we can conceive advertisements as objects which are enacted in different realities (legal, physical and so on) and different modes (an advert or a communications device) by actors seeking to pursue their interests. Having begun to chart this hinterland, one could now add a deeper analysis of the specific practices of actors that move objects between modes and open up or resist new realities. In this way, examining enacted realities and modes is one way to expose the ontological politics behind marketing objects. It allows us to expose the battles between interested actors over the mode of an object within a particular reality, its presence or absence in a reality, and the relationships between different modes and realities.

In the case analysed here, an advert not only exists in the network of relations illustrated in Figure 1 - and no doubt many more - but it never exists only as an advertising object. If the proposed object did not have a phone in it, it would not, in all likelihood, have come into existence as a physical object. It would be an advert and, as such, would have provided the LPA with the powers to reject the proposal without challenge. But once it became a physical object, 
the 'intended' function of providing telecommunications is manifest absent by virtue of its presence as advertising space.

\section{A sociological perspective on marketing media}

An advert exists in multiple contradictory modes within different social worlds. While it is widely acknowledged that adverts must reside, psychologically, in a liminal space between entertainment, information and persuasion to be most effective, the case explored here illustrates that to exist physically, an advert also has to exist in a liminal social space. Physically, economically, legally and in policy, the object changes from being an advert to being something else. The relations that enact these modes can then be exploited strategically by those actors pursuing their interests at the expense of others.

In this respect, a sociological theory of marketing media can draw heavily on Law's object theory, specifically his conceptualisation of fractional objects. As we have seen, Law defines a fractional object as more than one and less than many. This is not intuitive but it allows us through the limitations of thinking about marketing media in other terms such as materiality, representation or action. In terms of materiality, when we seek to understand an object in terms of what it is made from, we give priority to the physical world but we overlook how an object is used. In terms of representation, when an object is seen to describe its own reality, we give priority to subjects at the expense of objects. STS, under its various guises, overcomes these limitations by emphasizing the things objects do (see Harman, 2016). A fractional object, in contrast, can be material, representational and productive at the same time. It has multiple realities in different settings which interconnect in complex ways. 
In this respect, it is useful to distinguish between 'fractional' objects and the 'fractal' metaphor that so intrigued Strathern (1991). In Law's original conception this distinction is somewhat blurred. Indeed, he argues we can use fractals as one possible metaphor with which to apprehend and describe multiple relations 'without worrying too much about the mathematics' (Law 2002a: 3). Elsewhere, as we have seen, he refers to sediments or layers. But there are subtle differences between fractals, fractions and other metaphors that are important here. Indeed, a wider criticism of much of STS is that it borrows concepts from the natural sciences without detailing how they differ within social applications other than the absence of maths (see Sokal and Bricmont, 1998).

Fractal, in mathematics, emphasizes patterns. As a mathematical abstraction of geometry, its characteristic of recurring sets of relations within itself, no matter the scale or order of analysis, serves as a way to describe multiplicity. Indeed, it emphasises the self-similar relations within a seemingly single entity that we have described here; the repeating processes of making particular traits of the advertising object absent and present at different orders of analysis (in order to achieve conflicting objectives). It is, in effect, this repeating pattern - of splitting, separating, making one thing absent and other things present - that allows the marketing medium to 'exist'.

A fraction, in contrast, is simply a part of a whole and, thereby, suggests the kind of fragmentation that leaves continued faith in singularity intact. In Strathern's (2004: xxix) words, splitting objects into fractions or 'partitionings' overlooks the dynamic interactions between subjects and objects, individuals and society, knowledge and practice. Likewise, speaking of sediments or layers - as Law does at various times - implies a single relationship between different forms of an object based on depth. In turn, this suggests that we can eventually grasp a 
real object in its totality. Unfortunately, this misses the unique value of using the fractal metaphor - namely, that an object is never fully apprehended at one scale of investigation (i.e. within one enacted reality). Rather, we can best understand an object by looking at the relationships between different scales. There is a danger that the archaeological metaphors developed by Cochoy $(2010,2009)$ and Law (2009) can be taken too literally. They imply that there is a single underlying object that can be dug out of its social relations or that we can layer different existences until we have grasped a total understanding of the real, essential object.

To develop the analysis of fractal objects in marketing, without splitting them into discrete fractions, this study offers two interpretative concepts. First, it adds the notion of an enacted reality. Second, it argues that we can distinguish the enacted mode that an object performs in a given enacted reality. Neither concept requires much revision to dominant ideas within market studies (see Latour, 2013). However, they provide a useful analytic vocabulary with which to diagnose fractal objects. As fractal, the object contains all sets of recurring relations within itself (i.e. it is not a mere fragment of a larger whole). Thinking in terms of enacted realities and enacted modes avoids the trap of thinking about the layers or sediments of a single object. It has allowed us to see that an object can appear stable across different settings because of, not in spite of, its various enactments.

This line of thinking prompts us to consider whether all marketing objects are, necessarily, fractal. This is an open question. Certainly, advertising objects - which, up to now, have been thought to balance as a single entity between persuasion, entertainment, information and emotion - can now be seen as multiple, self-similar enactments produced within different sets of practices. Indeed, the fractal metaphor appears to be especially pertinent in understanding marketing media because it emphasizes that each enactment of a seeming singular entity includes 
all sets of relations but cannot be reduced to any one set. This suggests that marketing media, with their particular requirement to 'hide' their persuasive intent in order to persuade effectively, must be fractal to exist at all.

\section{Conclusion: Points of resistance and possibilities for new realities}

Understanding adverts as fractal objects provides new openings for critical interventions. A phone box that displays advertising rests on a hinterland that includes the procedures of securing planning permission from the local authority, the needs of advertisers, theoretical explanations and industry assumptions about the power of low involvement persuasion, the geographical characteristics of the target market, and more. If these realities seem solid, it is because relationships between them have spread, scattered, linked and stabilised. To apply Law's (2009: 248) terms, by now so much has been invested in the routines of outdoor advertising 'that it has become almost too expensive to undo them or the realities that they collaborate to make'.

Yet, in the hinterland, things are far from stable. Judges' decisions, planning regulations, advertising theory - these things can be changed and challenged (some more easily than others). In some realities, objects are enacted for other purposes than advertising. They may be protected cultural artefacts or design icons, or repurposed to meet social needs. Removing the adverts from their surface leaves the object unaffected.

However, in other enacted realities, the objects become more stable the more their status as adverts is challenged. In the present study, challenging the siting of phone boxes because of their ability to display advertisements served to disempower the local representatives, who sought to limit the presence of advertising on their streets, and empowered the advertising agency who wanted to construct more glass fronted displays in prominent city-centre locations. It 
might be better, then, for the grounds for enacting advertising media as a legal entity to be opened up for debate, perhaps made less real, and for the economic reality of adverts to be made more real. If, in the proposal and legal realities, the phone box could be provided with a hinterland of economic reality-enacting practices it would be performed quite differently. Those who are critical of advertising and focus on the physical object, might benefit from targeting the legal legitimacy of the object in exposing its failures in providing meaningful consumer choice and service (e.g. non-operational telephones, very low usage levels).

So, thinking about adverts as fractal objects also shows us the limitations of consumer power if it is contained purely within the physical reality. If consumer resistance worked against decisions and actions made by politicians, judges and ombudsmen, it might have more effect on advertising media than attacking the physical manifestations of adverts themselves. In summary, understanding the fractal nature of an object not only combines multiple perspectives on objects, it opens up new ways of approaching advertising media and allows us to consider different logics and imperatives that might have purchase in the different settings that enact the realities of an advert.

\section{References}

Araujo L (2007) Markets, market-making and marketing. Marketing Theory 7(3): 211-226.

Baker LE (2007) Public sites versus public sights: The progressive response to outdoor advertising and the commercialization of public space. American Quarterly 59(4): 1187-1213. 
Bolton N (2014) Phone Box Advertising. Bubble Outdoor - News. Available at: http://bubbleoutdoor.com/phone-box-advertising/ (Accessed 16th May 2018)

Brei V and Tadajewski M (2015) Crafting the market for bottled water: a social praxeology approach. European Journal of Marketing 49(3/4): 327-349.

Christensen BJ, Hillersdal L and Holm L (2017) Working with a fractional object: enactments of appetite in interdisciplinary work in anthropology and biomedicine. Anthropology \& Medicine 24(2): 221-235.

Cluley R and Brown SD (2015) The dividualised consumer: sketching the new mask of the consumer. Journal of Marketing Management 31(1-2): 107-122.

Cluley, R. (2018) 'The construction of marketing measures: The case of viewability', Marketing Theory, 18(3): $287-305$.

Cochoy F (2009) Driving a shopping cart from STS to business, and the other way round: On the introduction of shopping carts in American grocery stores (1936-1959). Organization 16(1): 31-55.

Cochoy F (2010) "HOW TO BUILD DISPLAYS THAT SELL": The politics of performativity in American grocery stores (Progressive Grocer, 1929-1946). Journal of Cultural Economy 3(2): 299-315.

Cochoy F (2016) On Curiosity: the art of market seduction. Manchester: Mattering Press.

Dahlén M and Edenius M (2007) When is advertising advertising? Comparing responses to nontraditional and traditional advertising media. Journal of Current Issues \& Research in Advertising 29(1): 33-42.

Denegri-Knott J and Tadajewski M (2010) The emergence of MP3 technology. Journal of Historical Research in Marketing 2(4): 397-425. 
Denegri-Knott J and Tadajewski M (2017) Sanctioning value: The legal system, hyper-power and the legitimation of MP. Marketing Theory 17(2): 219-240.

EWHC 3309 (2010) Infocus Public Networks Ltd v Secretary of State for Communities and Local Government \& Ors. Available from: http://www.bailii.org/ew/cases/EWHC/Admin/2010/3309.html (accessed 16th May 2018)

Freund J (2014) The Smiling Faces of Capital and the 3 Vortices of Hell. In: Brown S and Ponsonby-McCabe S (eds) Brand Mascots: And other marketing animals. London: Routledge, 255-266.

Friestad M \& Wright P (1999) Everyday persuasion knowledge. Psychology \& Marketing 16(2): 185-194.

Hagberg J (2015) Agencing practices: a historical exploration of shopping bags. Consumption Markets and Culture 19(1): 111-132.

Harman G (2016) Immaterialism: Objects and social theory. London: John Wiley \& Sons. Hawkins G (2011) Packaging water: plastic bottles as market and public devices. Economy and Society 40(4): 534-552.

Infocus Public Networks Ltd. (2014) Abbreviated accounts, $30^{\text {th }}$ November 2014. Available at: https://beta.companieshouse.gov.uk/company/06463216/filing-history (accessed 23rd May 2018)

Infocus Public Networks Ltd. (2015) Financial Statements, $31^{\text {st }}$ December 2015. Available at: https://beta.companieshouse.gov.uk/company/06463216/filing-history (accessed $23^{\text {rd }}$ May 2018) 
Iveson K (2012) Branded cities: outdoor advertising, urban governance, and the outdoor media landscape. Antipode 44(1): 151-174.

Jacobi E, Freund J and Araujo L (2015) Is there a gap in the market, and is there a market in the gap? How advertising planning performs markets. Journal of Marketing Management 31(1-2): 37-61.

Latour, B (2013) An inquiry into modes of existence. Boston: Harvard University Press. Law J (2002a) Aircraft Stories: Decentering the Object in Technoscience. Durham: Duke University Press.

Law J (2002b) Objects and Spaces. Theory, Culture and Society 19(5-6): 91-105.

Law J (2004) After Method: Mess in social science research. London: Routledge.

Law J (2007) Actor Network Theory and Material Semiotics. Version of 25th April 2007, Available at:

http://www.heterogeneities.net/publications/Law2007ANTandMaterialSemiotics. pdf (accessed 16th May 2018)

Law J (2009) Seeing Like A Survey. Cultural Sociology 3(2): 239-256.

Law J and Urry J (2004) Enacting the social. Economy and Society 33(3): 390-410.

Marketing Week (2002) BT hunts sales agency to handle kiosk ads business. 21st February, https://www.marketingweek.com/2002/02/21/bt-hunts-sales-agency-to-handlekiosk-ads-business-2/ (accessed 16th May 2018)

McFall L (2004) The Language of the Walls: Putting Promotional Saturation in Historical Context. Consumption Markets \& Culture 7(2):107-128. 
Ministry of Housing, Communities \& Local Government (2012) National Planning Policy Framework. Available at: https://www.gov.uk/government/publications/nationalplanning-policy-framework--2 (accessed 23rd May 2018)

Nottingham City Council (2013) Decision Notice 13/00980/PAT. Available at: http://publicaccess.nottinghamcity.gov.uk/onlineapplications/applicationDetails.do?activeTab=documents\&keyVal=MLNPEOLY0 0L00 (accessed 23 ${ }^{\text {rd }}$ May 2018)

Ofcom (2018) Direction under Section 106(3) of the Communications Act 2003 applying the electronic communications code in the case of In Focus Public Networks Limited. Available at: https://www.ofcom.org.uk/consultations-and-statements/category3/infocus (accessed 23rd May 2018)

Parkin D (2013) Installation of electronic communications apparatus on the Highway by an electronic communications code operator. Nottingham City Council, 13/00980/PAT. Available at: http://publicaccess.nottinghamcity.gov.uk/onlineapplications/applicationDetails.do?activeTab=documents\&keyVal=MLNPEOLY0 OL00 (accessed $23^{\text {rd }}$ May 2018)

Parry R (2011) The Ascent of Media: From Gilgamesh to Google via Gutenburg. London: Nicholas Brealey.

Registrar of Companies of England and Wales (2008) Certificate of Incorporation on change of name, company number $6463216,25^{\text {th }}$ November. Available at: https://beta.companieshouse.gov.uk/company/06463216/filing-history?page=3 (accessed 23 ${ }^{\text {rd }}$ May 2018) 
Sokal A D \& Bricmont J (1998) Intellectual impostures: postmodern philosophers' abuse of science, London: Profile Books.

Strathern M (2004/1991) Partial Connections. (Updated ed) Oxford: AltaMira.

Venter P. Wright A \& Dibb S (2015) Performing market segmentation: A performative perspective. Journal of Marketing Management 31(1-2): 62-83 doi:10.1080/ 0267257X.2014.980437 